\title{
Persoalan Kesetaraan Gender dalam Karya Seni Rupa Kontemporer Indonesia
}

\author{
Ira Adriati Winarno
}

\author{
Fakultas Senirupa dan Desain-ITB
}

\begin{abstract}
Abstrak. Art work serves not only for personal expression but also have social function. It is quite obvious as some Indonesian women artists use their art works to express gender equality issues. Their ideas are contributing greatly to the development of contemporary visual art in Indonesia. These women artists express issues of gender that whether personally experienced by them or other women in general, using the expressive style of surrealism, expressionism, and naturalism. Certainly, their art works show good aesthetics values, supported by excellent skills and technical abilities. Most of their art works not only provide excellent visualizations but also send strong messages on gender equality issues. Their works, as explained in this study, provide a common ground to increase public awareness for the importance of gender equality issues in Indonesia.
\end{abstract}

Keywords: women artists; gender equality; art works.

\section{$1 \quad$ Pendahuluan}

Karya seni rupa seringkali dianggap hanya sebatas ekspresi personal dari perupanya. Masih banyak yang tidak menyadari bahwa karya seni rupa walaupun merupakan ekspresi personal, tetap memiliki fungsi sosial yang dapat memaparkan berbagai situasi sosial dalam kehidupan manusia. Feldman menyebutkan, In a sense all works of art perform a social function, since they are created for an audience [1]. Karya seni bahkan bisa saja mempengaruhi pemikiran masyarakat melalui unsur-unsur visual yang terdapat dalam sebuah karya seni.

Perempuan perupa Indonesia saat ini memanfaatkan karya seni rupa sebagai media ekspresi pribadi. Beberapa di antara perempuan perupa tersebut, menggunakan karya seni sebagai media untuk mengungkapkan perhatiannya terhadap berbagai persoalan gender.

Tulisan ini akan memaparkan tentang karya-karya perempuan perupa Indonesia yang mengangkat persoalan kesetaraan gender. Memaparkan tema yang mereka pilih, nilai estetis dalam karya seni perempuan perupa Indonesia, dan pengaruhnya pada persepsi masyarakat terhadap persoalan gender.

Received June $14^{\text {th }} 2007$, Revised July $24^{\text {th }} 2007$, Accepted for publication August $14^{\text {th }} 2007$. 


\section{$2 \quad$ Kesetaraan Gender}

Mengapa kesetaraan gender digaungkan dalam berbagai media secara internasional? Apakah memang tidak ada kesetaraan antara perempuan dan pria dalam kehidupan ini? Banyak kasus yang memperlihatkan ketimpangan tersebut. Beberapa contoh yang tampak adalah keberadaan perempuan di parlemen yang tidak sebanding dengan jumlah pria, tidak tercatatnya perempuan dalam historiografi suatu negara, maupun tindak kekerasan dalam rumah tangga sebagai akibat ketidaksejajaran istri dan suami.

Di Indonesia khususnya dalam struktur kehidupan beberapa suku di masa lampau, kesetaraan gender telah diwujudkan. A. Nunuk P. Murniati [2], memaparkan berdasarkan tulisan Peacock bahwa sistem masyarakat Jawa adalah bilineal, yakni posisi perempuan dan laki-laki setara dalam mengambil keputusan. Hal yang sama dapat dilihat pada masyarakat Sunda, Aceh, Iban, Mananjan, dan Ambon.

Masih dalam penuturan A. Nunuk P. Murniati [2], bahwa pergeseran struktur dari bilineal menjadi patriarki dipengaruhi oleh agama Kristen yang "mensucikan" kawin somah. Dalam ajaran tersebut, istri hanya satu dan ia adalah milik suami. Ajaran tersebut berpengaruh pada konsep bilineal di beberapa kawasan Papua. Tampaknya tidak hanya agama Kristen, tetapi seluruh agama-agama semit (Yahudi, Nasrani, Islam) telah mempengaruhi masyarakat untuk menganut struktur patriarki. Nasarudin Umar [3] memaparkan bahwa setiap agama tidak diturunkan di dalam masyarakat yang hampa budaya, melainkan terhadap masyarakat yang sudah sarat dengan nilai-nilai budaya. Agama-agama semit turun di dalam masyarakat yang androsentris, di mana relasi gender didominasi oleh kaum laki-laki. Oleh karena itu tidak mengherankan jika tafsiran ajaran agama sangat dipengaruhi oleh budaya di mana agama tersebut pertama kali diturunkan.

Pengaruh patrilineal di Jawa khususnya di sekitar Yogyakarta dan Solo, karena pengaruh feodal, melalui ajaran Mangkunegaran IV. Hubungan setara perempuan dan laki-laki, berubah menjadi hubungan subordinasi.

Denys Lombard salah satu penulis historigrafi Indonesia memaparkan bahwa meskipun tidak ada kesimpulan mutlak yang dapat ditarik dari kutipan Xin Tangshu yang menyatakan bahwa pada tahun 674 penduduk Heling (Jawa) mempunyai ratu yang bernama Sima (Xi-mo), terdapat juga beberapa prasasti yang dengan jelas menyebut bangunan-bangunan yang didirikan oleh "raturatu” (bini-haji) [4]. 
Paparan di atas memperlihatkan bahwa pada dasarnya berbagai suku di Indonesia sebelum bergesekan dengan budaya luar termasuk pemikiran keagamaan, menganut prinsip bilineal. Akulturasi budaya menyebabkan pergeseran struktur sosial bilineal menjadi patriarki.

Pergeseran struktur sosial dalam masyarakat tersebut menyebabkan perempuan seringkali tersubordinasi. Kekerasan secara fisik maupun mental dirasakan oleh kaum perempuan di Indonesia maupun berbagai negara di dunia. Oleh karena itu tidak mengherankan jika Perserikatan Bangsa-bangsa (PBB) merasa perlu mencanangkan program kesetaraan gender yang tertuang dalam The Eight Millenium Development Goals (MDGs) 2015. Dalam MDGs 2015 urutan ketiga yaitu Promote gender equality and empower women (Mempromosikan kesetaraan gender dan pemberdayaan perempuan).

Indonesia sebagai salah satu anggota Perserikatan Bangsa-bangsa termasuk negara yang harus memenuhi target MDGs 2015 tersebut. Berbagai bentuk kegiatan dilakukan untuk memenuhi target tersebut. Beberapa perempuan perupa Indonesia melalui karya-karyanya, telah mengangkat tema-tema yang berkaitan dengan persoalan gender. Karya-karya mereka diharapkan dapat mempengaruhi pemikiran masyarakat tentang pentingnya kesetaraan gender untuk kehidupan manusia yang lebih baik.

\section{Para Pelopor Perempuan Perupa Indonesia}

Perempuan perupa Indonesia yang berkiprah dengan visualisasi seni rupa modern diawali oleh Kartini dan kedua adiknya. Guru melukis mereka adalah seorang perempuan Belanda yang memiliki keahlian melukis secara realis. Karya-karya Kartini, Rukmini, dan Kardinah berupa karya seni lukis naturalis dengan obyek-obyek di sekeliling mereka seperti kucing, tumbuhan, maupun keindahan alam.

Emiria Sunassa adalah perempuan perupa yang masuk dalam kelompok PERSAGI (Persatuan Ahli Gambar Indonesia). Beberapa karyanya merekam budaya seni Indonesia. Perempuan perupa lain yang tidak dikenal masyarakat adalah Mia Bustam, ia adalah istri pertama pelukis Sudjojono. Setelah perceraiannya, perempuan ini justru mampu mengembangkan keahlian melukisnya. Karya-karyanya memperlihatkan kemahirannya dalam melukis secara naturalis. Mia Bustam bergabung dengan Sanggar Seniman Indonesia Muda di Yogyakarta untuk mengembangkan bakat melukisnya.

Selanjutnya jumlah perempuan perupa Indonesia semakin bertambah, sejalan dengan berdirinya sekolah formal seni rupa di Indonesia. Perempuan perupa yang menempuh pendidikan di Seni Rupa Institut Teknologi Bandung periode 
tahun 1960-1970-an, memunculkan nama Farida Srihadi, Erna Pirous, Umi Dachlan, dan Heyi Ma'mun sebagai perempuan perupa dengan visualisasi karya abstrak. Penghayatan kepada alam, perenungan pribadi, maupun penghormatan pada budaya tradisi menjadi pilihan tema mereka.

Di Yogyakarta, dikenal nama Kartika Affandi yang memvisualisasikan karyakaryanya dengan gaya ekspresionis serupa dengan ayahnya. Karya-karyanya merekam berbagai fenomena alam, benda-benda di sekitar, anggota keluarganya, dan karya-karya periode tahun 1990an ia berani mengungkapkan perasaan tertekan yang ia rasakan dalam menghadapi persoalan ketidakadilan gender dalam rumah tangganya.

Seri karya berjudul Self Portrait (1-7). Pada karya Self Portrait 1-6 ia melukiskan wajah dirinya dengan warna putih, krem, dan sedikit kuning muda. Dalam karya Self Portrait 7, Kartika seakan telah menemukan kembali kepercayaan dirinya dengan menyimbolkan dirinya dengan bunga matahari dan matahari yang memperlihatkan wajah ayahnya.Melalui karya-karya Kartika tersebut, dapat ditangkap bahwa seri Self Portrait 1-7 (1999) adalah ungkapannya tentang tindak ketidakadilan yang ia rasakan oleh suaminya.

Perempuan perupa lainnya yang berasal dari Yogyakarta yang menempuh pendidikan di Akademi Seni Rupa Indonesia (ASRI) adalah Ida Hadjar. Dalam buku Indonesian Heritage: Seni Rupa [5], dinyatakan bahwa Ida Hadjar memiliki ciri melukis secara figuratif. Ia melukiskan berbagai aktifitas rakyat seperti para penari Jaran Kepang. Karyanya yang lain merekam peristiwa tragedi Sinila yang tertuang dalam Tragedy Sinila, 1980.

Dalam seni patung, beberapa pematung yang memperoleh pendidikan tinggi seni rupa, seperti Edi Ratna mengungkapkan memikirannya melalui visualisasi abstrak dengan media kayu. Salah satu karyanya berjudul Dialogue in Wood, 1987.

Pada periode tahun 1974-1979 terjadi peristiwa menarik dalam dunia seni rupa Indonesia yaitu peristiwa protes seniman muda terhadap keputusan dewan juri Biennale Seni Lukis Indonesia II tahun 1974. Gerakan mereka kemudian dikenal dengan istilah Gerakan Seni Rupa Baru. Salah satu perempuan perupa yang termasuk dalam gerakan tersebut adalah Siti Adiyati. Karyanya berjudul Child's Game (1977), memperlihatkan alat permainan coklak atau dakon dengan dinding digambar tangan yang sedang menjatuhkan kerang-kerang untuk permainan tersebut.

Melalui pemaparan beberapa karya perempuan perupa pada masa awal, ternyata tidak tampak nyata keinginan memanfaatkan karya seni rupa sebagai media 
untuk mengungkapkan persoalan kehidupan perempuan dalam kaitan relasi perempuan dan pria khususnya persoalan gender.

Mia Bustam yang mulai mengembangkan bakat pada saat kehidupan rumah tangganya mengalami kehancuran, dalam buku biografinya, tidak menjelaskan apakah mengungkapkan kegalauannya melalui karya lukis. Selama periode keretakan rumah tangganya, ia hanya memaparkan bahwa ia melukiskan sosok anak-anaknya dan dirinya sendiri.

Tabel 1 Kecenderungan tema dalam karya perempuan perupa Indonesia.

\begin{tabular}{|c|c|c|c|}
\hline Tahun & $\begin{array}{c}\text { Tema \& Gaya } \\
\text { Visual }\end{array}$ & Perupa & Keterangan \\
\hline 1900-an & $\begin{array}{l}\text { Keindahan alam - } \\
\text { naturalis }\end{array}$ & $\begin{array}{l}\text { Kartini, Rukmini, } \\
\text { Kardinah }\end{array}$ & $\begin{array}{l}\text { Pengaruh dari pelukis } \\
\text { Belanda }\end{array}$ \\
\hline $\begin{array}{l}1930- \\
1950 \text { an }\end{array}$ & $\begin{array}{l}\text { Keindahan alam \& } \\
\text { seni budaya } \\
\text { Indonesia - naturalis } \\
\end{array}$ & $\begin{array}{l}\text { Emiria Sunassa, } \\
\text { Trijoto Abdullah, } \\
\text { Mia Bustam } \\
\end{array}$ & $\begin{array}{l}\text { Emiria anggota PERSAGI, } \\
\text { Mia anggota SIM }\end{array}$ \\
\hline 1960-an & $\begin{array}{l}\text { Kekaguman pada } \\
\text { alam, perasaan } \\
\text { pribadi - abstrak, } \\
\text { figuratif, } \\
\text { ekspresionis }\end{array}$ & $\begin{array}{l}\text { Kartika Affandi, } \\
\text { Umi Dachlan, } \\
\text { Farida Srihadi, } \\
\text { Erna Pirous, Ida } \\
\text { Hadjar }\end{array}$ & $\begin{array}{l}\text { Cukup banyak mahasiswi di } \\
\text { Perguruan Tinggi Seni } \\
\text { Perupa dari Bandung } \\
\text { cenderung abstrak } \\
\text { Perupa dari Yogyakarta } \\
\text { cenderung figuratif } \\
\end{array}$ \\
\hline $\begin{array}{l}\text { 1970-an - } \\
1980-\text { an }\end{array}$ & $\begin{array}{l}\text { Kekaguman pada } \\
\text { alam, perasaan } \\
\text { pribadi, persoalan } \\
\text { sosial - abstrak, } \\
\text { figuratif, } \\
\text { ekspresionis } \\
\end{array}$ & $\begin{array}{l}\text { Nunung WS., } \\
\text { Nanik Mirna, Edith } \\
\text { Ratna, Heyi } \\
\text { Ma'mun, Siti } \\
\text { Adiati, Yanuar } \\
\text { Ernawati, d ll } \\
\end{array}$ & $\begin{array}{l}\text { Hanya beberapa perempuan } \\
\text { perupa yang dipilih sbg } \\
\text { sampel }\end{array}$ \\
\hline $\begin{array}{l}\text { 1990-an - } \\
\text { 2000an }\end{array}$ & $\begin{array}{l}\text { Persoalan sosial, } \\
\text { banyak yang } \\
\text { mengangkat } \\
\text { persoalan gender - } \\
\text { visualisasi surealis, } \\
\text { figuratif, simbolis }\end{array}$ & $\begin{array}{l}\text { Dolorosa Sinaga, } \\
\text { Astari Rasjid, } \\
\text { Arahmaiani, Lucia } \\
\text { Hartini, Iriantine } \\
\text { Karnaya, IGK } \\
\text { Murniasih }\end{array}$ & $\begin{array}{l}\text { Beberapa perempuan } \\
\text { perupa dlm sampel ini telah } \\
\text { berkarier sejak tahun 1980- } \\
\text { an, tetapi lebih menonjol } \\
\text { dgn tema gender tahun } \\
\text { 1990an, sehingga masuk } \\
\text { periode ini. }\end{array}$ \\
\hline
\end{tabular}

Dalam Tabel 1 diperlihatkan kemunculan tema persoalan gender secara nyata dalam karya perempuan perupa Indonesia. Dalam setiap periode tidak berarti tema lama ditinggalkan, beberapa perempuan perupa tetap konsisten dengan tema awal yang mereka pilih, tetapi perempuan perupa lainnya mengikuti arus utama. Sebagai contoh Kartika Affandi mengangkat persoalan pribadi dalam karya-karyanya baru dalam periode tahun 1990-an, padahal sebelumnya ia mengalami persoalan rumah tangga pula dalam perkawinan pertamanya.Tabel 
ini juga memperlihatkan secara garis besar bahwa tema sosial yang berkaitan dengan persoalan gender, baru benar-benar muncul sebagai tema karya perempuan perupa Indonesia pada periode tahun 1990-an. Nama perempuan yang tertulis berupa sampel dari sekian banyak perempuan perupa Indonesia.

Ketidakberanian mengangkat persoalan rumah tangga atau relasi dengan pria (persoalan gender) ke dalam karya perempuan perupa pada masa awal, kemungkinan besar karena masyarakat masih menabukan persoalan rumah tangga untuk diungkapkan dan diketahui oleh orang lain. Selain itu jika melihat kebijakan pemerintah Orde Baru yang berkuasa sejak tahun 1966 - 1998, secara nyata mendudukkan perempuan sebagai pendamping suami. J.J. Rizal dalam tulisannya menyatakan bahwa Sejak itu (sejak terbitnya enam jilid Sejarah Nasional Indonesia yang diterima oleh Presiden Soeharto 18 Maret 1976), historiografi Indonesia melulu berisi sejarah perempuan yang tidak mengganggu patriarki militer, perempuan sebatas "konco wingking" (teman di belakang) yang setia pada penguasa [6].

\section{Tema Persoalan Kesetaraan Gender dalam Seni Rupa}

Periode tahun 1990-an, mulai tumbuh kesadaran dalam diri perempuan perupa untuk memanfaatkan karya seni rupa sebagai media ekspresi mengungkapkan berbagai persoalan gender yang mereka rasakan. Kemungkinan besar keberanian tersebut muncul sejalan dengan maraknya pembahasan feminisme dan persoalan gender dalam ilmu sosial.

Pada akhir tahun 1990, Universitas Indonesia membuka Program Magister Kajian Wanita. Dengan demikian semakin memperkuat asumsi bahwa pada tahun 1990 merupakan titik awal kesadaran dunia akademis di Indonesia untuk mengembangkan pengetahuan tentang perempuan. Secara tidak langsung memperkokoh fenomena memahami persoalan perempuan dari sudut pandang perempuan itu sendiri.

Dampak kesadaran bahwa perempuan selama ini menjadi warga negara kelas dua berdampak pula pada dunia kesenirupaan Indonesia. Selain itu jika memperhatikan proses kemunculan posmodern, isu gender adalah salah satu tema yang diusung. Tidak mengherankan jika dalam perkembangan seni rupa kontemporer Indonesia, perempuan perupa tersadarkan untuk mengangkat persoalan gender dalam karya seni mereka.

Yustiono [7] dalam tulisannya memaparkan bahwa pada aspek ide, seni rupa kontemporer menampakkan sosok penentang arus dominasi modernisme, hal ini dapat dipandang sebagai hadirnya asas ganda. Pada aspek ide ini, kecenderungan untuk menyerap pikiran-pikiran posmodernisme juga nampak 
kuat. Hal itu nampak misalnya pada idiom-idiom yang sering dipakai seperti plural, etnik, multikulturalisme, gender, marginal, dan lain-lain.

Idiom gender tampak nyata sebagai tema pada perkembangan seni rupa kontemporer Indonesia. Perempuan perupa seperti Lucia Hartini, Arahmaiani, Astari Rasjid, Iriantine Karnaya, Dolorosa Sinaga, Marida Nasution, hingga perupa yang lebih muda seperti Bunga Jeruk dan Laksmi Sitoresmi mengangkat tema tersebut.

Arahmaiani secara tegas menyatakan bahwa karya-karyanya merupakan bentuk kesadarannya akan ketidakadilan gender yang dirasakan oleh perempuan. "Sesuai dengan kapasitasku sebagai perempuan, demikian juga dalam memahami aspek kehidupan yang akan saya angkat dalam seni rupa, saya mencoba menyuarakan permasalahan dari golongan tertindas. Maka dari itu permasalahan tersebut saya tampilkan dengan memakai metafor gender". Menurutnya pola penindasan antara penguasa dan rakyat yang tertindas atau antara yang kuat dan yang lemah, sama dengan hubungan antara laki-laki dan perempuan yang selalu tersubordinasi [8].
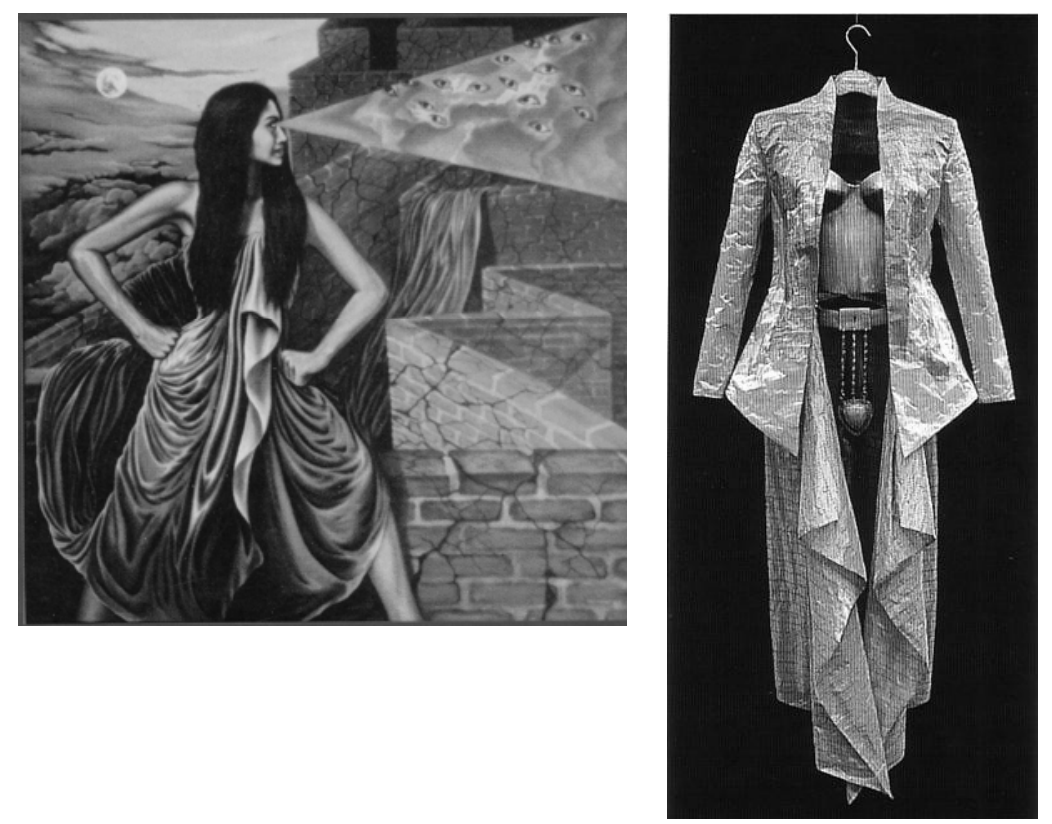

Gambar 1 (a) Lucia Hartini, Srikandi, 1993, 150 x $150 \mathrm{~cm}$, cat minyak di atas kanvas; (b) Astari Rasjid, Prettified Cage, 1998 (Sumber: Marianto, D. Surealisme Yogyakarta, Rumah Penerbitan Merapi, Yogyakarta, 2001; Katalog Women in the Realm of Spirituality, 1998). 
Lucia Hartini memaparkan persoalan hidupnya dalam beberapa karya periode tahun 1990-an. Salah satunya karya berjudul Srikandi (1993). Memvisualisasikan sosok dirinya yang sedang bertolak pinggang, dengan latar belakang tembok-tembok dan pemandangan langit dan bulan. Banyak mata mengamatinya. Pada saat karya tersebut dikerjakan, Lucia Hartini mendapat goncangan dalam hubungannya dengan suaminya, tetapi berusaha tegar menghadapi persoalan hidup tersebut. Ia tidak bergantung kepada suaminya lagi, ia memenuhi kebutuhan rumah tangga dan merawat kedua anaknya sendiri. Lucia mengungkapkan: "Saya ingin tunjukkan bahwa kesendirian tak perlu membuat takut dalam mengarungi hidup. Keagungan Tuhan lewat jagat raya ini senantiasa melindungi kita."
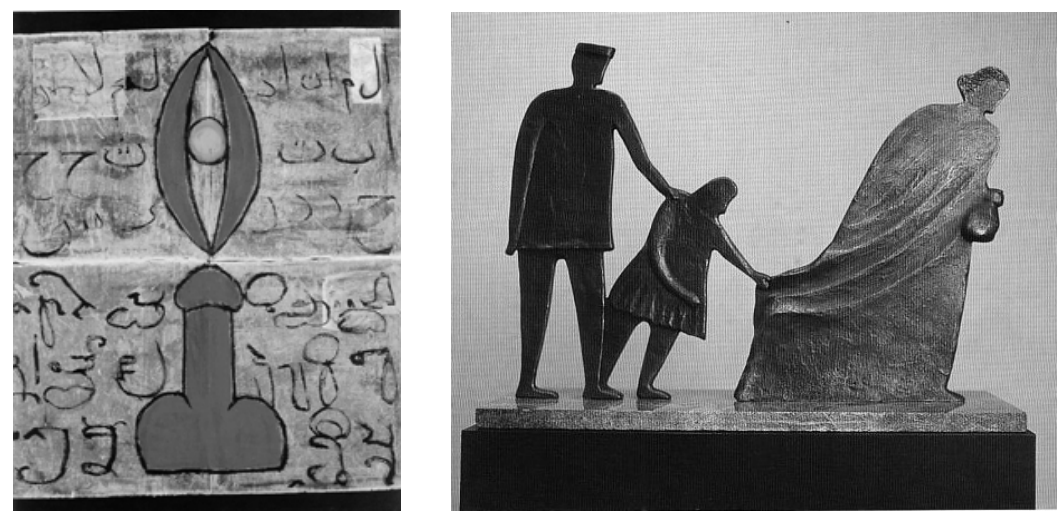

Gambar 2 (a) Arahmaiani, Lingga-Yoni, 1994 Akrilik di atas kanvas, $182 \mathrm{x}$ 140 cm; (b) Iriantine Karnaya, I'm Leaving, 1995 patung metal, 45 x 61 x 5 cm (Sumber: Supriyanto, E. \& Bollansee, M., Indonesian Contemporary Art Now, SNP International, Singapore, 2007; Katalog Women in the Realm of Spirituality, 1998.

Astari Rasjid memvisualisasikan pandangannya selama hidup dalam kungkungan budaya Jawa yang kuat. Astari berbicara mengenai posisi perempuan yang terkadang tidak memiliki nilai tawar. Salah satu karyakaryanya dalam periode awal adalah Temple of Efflorescence, 1996. Memperlihatkan sosok perempuan berpakaian pengantin Jawa memegang bunga teratai merah dengan latar belakang candi Borobudur. Karya-karyanya periode tahun 2000an, mulai mengganti latar belakang budaya Jawa dengan persoalan budaya masa kini dengan penggunaan ikon produk tas yang seringkali menjadi pengukur gengsi di antara kaum perempuan. Salah satunya dalam karya berjudul Envy (2006).

Astari Rasjid sangat peka terhadap situasi sosial budaya di Indonesia yang berkaitan dengan kaum perempuan. Setelah peristiwa kerusuhan Mei 1998, ia 
membuat seri karya yang berhubungan dengan kekerasan terhadap kaum perempuan etnis Cina, salah satu karyanya berjudul False Target (1998) dan Prettified Cage (1998). Karya Prettified Cage berupa karya tiga dimensi yang memperlihatkan bentuk kebaya, kain dan alat untuk mengunci kemaluan perempuan.

Arahmaiani pada tahun 1994 dengan berani memvisualisasikan genital perempuan dan laki-laki dalam lukisannya yang berlatar belakang huruf-huruf Arab. Karya tersebut berjudul Lingga Yoni yang dalam agama Hindu merupakan simbol laki-laki dan perempuan. Keberaniannya mengungkapkan bagaimana perempuan tertindas dalam kehidupan melalui karya-karyanya tentu dengan harapan masyarakat berani mengakuinya untuk memperbaiki kehidupan ini agar menjadi lebih adil.

Iriantine Kanarya dan Dolorosa Sinaga, dua orang pematung yang memilih tema persoalan perempuan dalam karyanya. Iriantine membuat patung sesosok perempuan yang mengandung akibat perkosaan dalam karya berjudul Victimized (1998). Ia juga memotret para perempuan yang terpaksa menjadi Tenaga Kerja Indonesia (TKI) karena beban ekonomi yang harus mereka tanggung. Perempuan yang menjadi TKI harus rela berpisah dengan anak dan suami mereka. Visualisasi kondisi tersebut terlihat dari karya berjudul I'M LEAVING (1995).
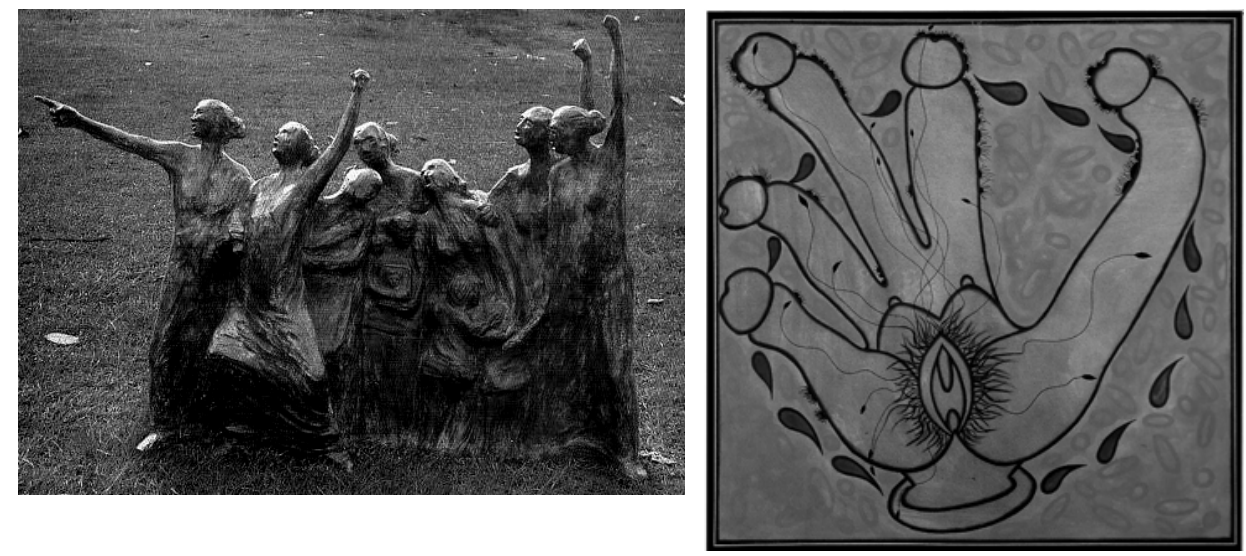

Gambar 3 (a) Dolorosa Sinaga, Avante!, 2003 Bronze, 107 x 43 x 81 cm; (b) IGAK Murniasih, Waiting, 2003, cat skrilik pada kanvas, 100 x $100 \mathrm{~cm}$ (Sumber: Katalog Pameran Via Dolorosa, Nadi Gallery, 9 April - 13 Mei 2003; Supriyanto, E. \& Bollansee, M., Indonesian Contemporary Art Now, SNP International, Singapore, 2007). 

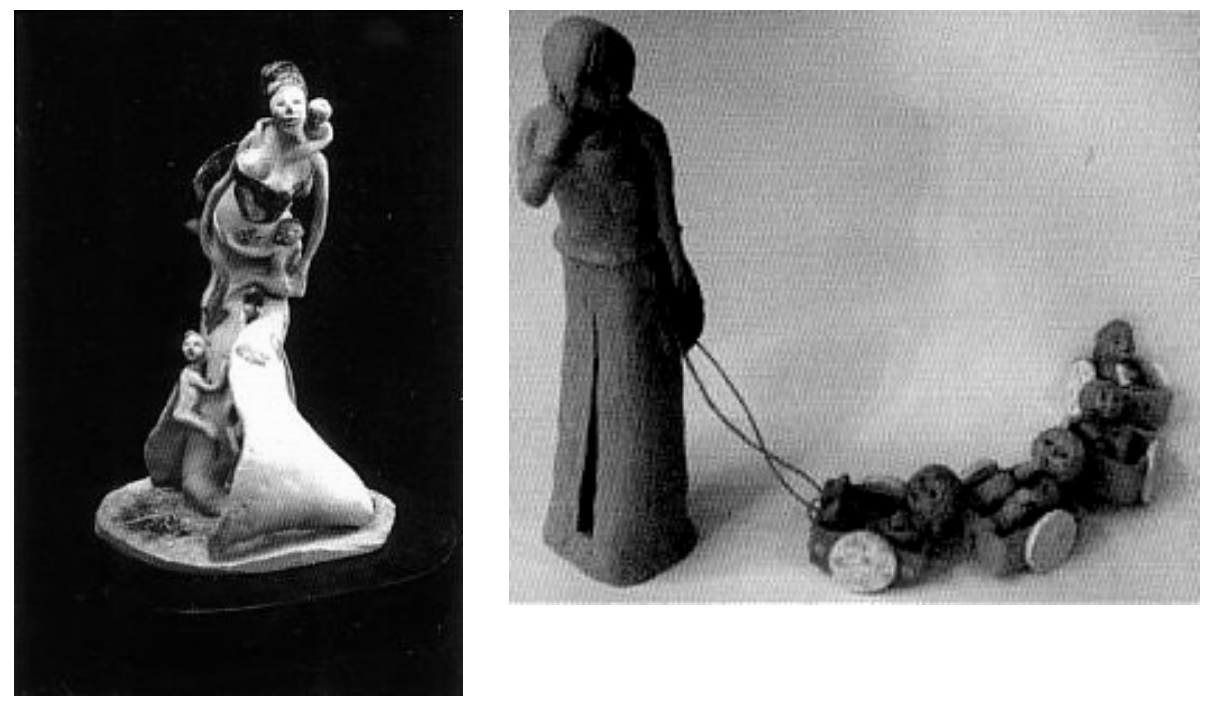

Gambar 4 (a) Ika W. Burhan, Wonder Women, 2006, 37 x 39 cm, stoneware, cobalt blue, iron oxide, slab, pinch; (b) Ira Suryandari, Oh....Maaa....!, 2007, 35.5 x 42 cm, stoneware, grog, coil, slab, slip (Sumber: Katalog Pameran Patung Keramik It's Fun 2b a Womanemara 6 Galeri, 25 April -15 Mei 2007; Katalog Pameran Patung Keramik It's Fun 2b a Womanemara 6 Galeri, 25 April -15 Mei 2007)

Dolorosa Sinaga dengan patung perunggu berukuran kecil membicarakan perempuan yang tertindas atau perempuan memiliki kekuatan dengan menggalang kebersamaan di antara kaum perempuan. Karya-karyanya dalam Pameran Tunggal berjudul Via Dolorosa tahun 2003, mengungkapkan ketidakadilan yang diterima perempuan pada satu sisi dan di sisi yang lain memberikan gambaran kekuatan perempuan. Contoh karyanya berjudul Avante (2003), memperlihatkan tujuh perempuan dengan anak-anak mereka, seakan berteriak untuk memperoleh keadilan melalui visualisasi tangan mereka yang mengepal dan menunjuk.

Seorang perempuan perupa yang berani melukiskan genital perempuan dan pria dalam karya-karyanya adalah IGAK Murniasih (almarhum). Bukan untuk mengumbar sesuatu yang porno, tetapi berbicara tentang berbagai tekanan psikologis dari persoalan kekerasan seksual yang diterimanya. Kreativitasnya membuat karya Murniasih menjadi unik, dengan warna-warna yang fantastik, komposisi yang tidak biasa, sehingga menjauhkan pemikiran pengamat tentang pengeksposan genital manusia.

Melalui karya, Murniasih mengajak masyarakat untuk jujur bahwa ada sebagian orang merasakan kekerasan seksual tersebut. Tidak mungkin 
diungkapkan, tetapi terlalu sakit untuk dirasakan. Karya seni merupakan terapi bagi dirinya sendiri untuk melupakan masa kelam yang pernah dialami.

Pada bulan Mei 2007, dua orang perempuan perupa Ira Suryandari dan Ika W. Burhan mencoba memotret keseharian perempuan Indonesia yang tinggal di perkotaan. Mereka melukiskan bagaimana para perempuan berarisan, pergi ke tempat sauna (spa), atau melukiskan keinginan untuk langsing, maupun kesibukan mengurus anak.

Karya keramik yang menampilkan figur-figur perempuan dengan kesehariannya tersebut seakan tidak membicarakan konflik kesetaraan gender. Hanya saja, setelah direnungkan, sebenarnya mereka pun ingin membicarakan betapa menjadi perempuan terkadang terbebani dengan berbagai tuntutan dari luar dirinya, seperti tuntutan untuk tampil cantik dengan tubuh langsing, mereka harus ke spa untuk menjadi perempuan cantik tadi. Siapa yang menuntut? Tentu saja pria dan juga perempuan lain di sekeliling mereka, padahal tak banyak perempuan menuntut pria untuk tetap tampan dan langsing.

Para perupa perempuan tersebut juga berbicara tentang beratnya tugas sebagai perempuan yang telah menjadi ibu. Mereka takkan pernah hanya memikirkan dirinya sendiri, karena mereka akan seantiasa dibebani oleh tugas mengurus anak-anak mereka. Di sisi lain, seorang bapak hampir tak pernah merasakan tugas tersebut. Dengan demikian, sebenarnya para perupa itu membicarakan persoalan kesetaraan gender pula.

Perbedaan generasi tampaknya membentuk cara pandang dalam mengungkapkan persoalan yang berat dalam visual yang terasa santai, keseharian, dan seakan tanpa persoalan. Wonder Women (2006) karya Ika W. Burhan divisualisasikan dengan sosok perempuan dengan balita yang menggayut di tubuhnya. Masih mengangkat tentang beban seorang ibu, Ira Suryandari dalam karya Oh....Maaa....! (2007) diwujudkan dalam sosok perempuan yang menarik gerobak berisi empat anak-anaknya.

Masih banyak perempuan perupa Indonesia yang memilih tema-tema persoalan kesetaraan gender. Perempuan perupa di atas hanyalah beberapa contoh yang dapat dipaparkan.

Setelah peristiwa kelam Kerusuhan Mei 1998, perempuan perupa Indonesia dan beberapa pria perupa secara tegas mengungkapkan keprihatinan dan ketidaksetujuan mereka terhadap kekerasan yang dialami banyak perempuan khususnya mereka yang beretnik Cina dalam sebuah pameran. Pameran Ekspresi 18 perupa; Menyikapi Kekerasan Terhadap Perempuan di Cemara 6 
Galeri, Jakarta 2 - 12 Desember 1998. Kegiatan tersebut memberikan gambaran bahwa perempuan dapat menyatakan sikap melalui karya seni rupa.

Keberanian mereka mengangkat persoalan gender dalam karya seni, merupakan salah satu cara untuk memperlihatkan kepada masyarakat bahwa ketimpangan gender itu terjadi dalam masyarakat Indonesia. Jika Hélène Cixous seorang tokoh feminis, meminta perempuan untuk menuliskan pengalamannya sebagai perempuan melalui medium sastra atau bahasa, maka perempuan perupa harus melukiskannya melalui bahasa visual dengan medium karya seni. Supaya semakin banyak lapisan masyarakat menyadari tentang adanya manusia perempuan yang memiliki peran dalam peradaban, dan saat ini para perupa itu belum memperoleh kesetaraan.

\section{$5 \quad$ Simpulan}

Tema persoalan gender yang diangkat oleh perempuan perupa Indonesia dapat divisualisasikan tanpa mengenyampingkan kemampuan estetis. Beragam media dan bentuk visualisasi yang penuh pertimbangan estetis dilakukan oleh perempuan perupa Indonesia, seperti dengan menggunakan media cat minyak, akrilik, keramik, logam, dan lain sebagainya. Kemudian gaya visualisasi naturalis, simbolis, figuratif, maupun surealis, dipilih untuk mendukung tema kesetaraan gender.

Keberanian mengangkat persoalan gender dalam karya seni rupa di Indonesia sejalan dengan perkembangan seni rupa kontemporer secara global. Keberanian ini dapat menjadi terapi pribadi karena membantu menyalurkan beban mental yang dirasakan oleh perempuan perupa seperti Kartika Affandi, IGK. Murniasih, atau Lucia Hartini.

Di sisi lain, karya seni para perupa perempuan dapat membantu membuka wawasan masyarakat tentang pentingnya kesetaraan gender dalam kehidupan. Meskipun demikian terdapat kesadaran bahwa karya seni tidak akan mengubah sebuah situasi secara instan, tetapi sebuah karya seni dapat menjadi sebuah stimulus dalam berbagi atau menganjurkan sebuah pemikiran, kegembiraan, maupun perasaan duka cita.

\section{Daftar Pustaka}

[1] Edmund Burke Feldman. 1967. Art as Image and Idea, Prentice -Hall, Inc., Englewood Cliffs, New Jersey, h. 36.

[2] Murniati. 2004. Getar Gender, Perempuan Indonesia dalam Perspektif Agama, Budaya, dan Keluarga, Indonesiatera, Magelang, h. 89. 
[3] Nasarudin Umar. 2000. Penafsiran Kitab Suci Berwawasan Jender: Tinjauan Terhadap Ragam dan Bias Interpretasi Teks Al- Qur'an dalam Perempuan Indonesia dalam Masyarakat yang Berubah, Program Studi Kajian Wanita, Universitas Indonesia, Jakarta, h. 169.

[4] Denys Lombard. 1996. Nusa Jawa: Silang Budaya: Warisan-warisan Kerajaan Kosentris, Gramedia Pustaka Utama, Jakarta, h. 92.

[5] Hildawati Soemantri, ed.. 2002. Indonesian Heritage: Seni Rupa, ed. Indonesia, Buku Antar Bangsa, Jakarta.

[6] J. J. Rizal, Jejak Perempuan dalam Historiografi Indonesia, dimuat dalam Jurnal Perempuan No.52, h 31.

[7] Yustiono. 1995. Seni Rupa Kontemporer Indonesia dan Era Asia Pasifik, dalam Jurnal Seni Rupa FSRD ITB, volume II/1995 .

[8] FX. Harsono. 2003. Kerakyatan dalam Seni Lukis Indonesia: Sejak PERSAGI hingga Kini dalam Politik dan Gender: Aspek-aspek Seni Visual Indonesia, Yayasan Seni Cemeti, Yogyakarta, h. 76 . 